\title{
ANALISIS KEPUTUSAN PERSEDIAAN ES BALOK DI PELABUHAN PERIKANAN PANTAI TUMUMPA KOTA MANADO Derma $^{1}$; Swenekhe S. Durand ${ }^{2}$; Lexy K. Rarung ${ }^{2}$ \\ 1) Mahasiswa Fakultas Perikanan dan IImu Kelautan Universitas Sam Ratulangi, Manado. \\ 2) Staff Pengajar Fakultas Perikanan dan IImu Kelautan Universitas Sam Ratulangi, Manado. Koresponden email: derma_hutagalung@yahoo.com
}

\begin{abstract}
Marine and fishery sector has great potential as a leading sector and the main driver of regional economic development towards North Sulawesi be advanced, independent and prosperous. This is because this sector has a comparative advantage over other sectors of the availability of great natural resources and has tremendous economic potential, that capable of produce products and services with high competitiveness, as long as it can manage it appropriately. According to the Ministry of Marine Affairs and Fisheries (KKP), the availability of natural resources in the land are increasingly limited, especially land-based, in line with the increasing population and the development of economic activities as the impact of the implementation of development. The purpose of the research is to know how to make decisions from the ice block inventory and to identify what influences inventory decisions at Tumumpa Fishery (PPP) in Manado City. The method used in this research is survey method and participative method. The data collected in the form of primary data and secondary data and data analysis used is descriptive qualitative analysis and quantitative descriptive analysis.

Fishery ports are special ports used as fishing bases and equipped with various facilities since fish are landed until distributed. The Fisheries Port (PPP) is located at Tumumpa II Subdistrict, Tuminting district, Manado City has geographical location $1^{\circ} 31^{\prime 2} 21^{\prime \prime N L}$ and $124^{\circ} 50^{\prime} 28^{\prime \prime} \mathrm{EL}$, with distance from downtown about $7 \mathrm{~km}$. The location of 4 (four) Ha areas that was built since 1993, known as the Fish Landing Base (PPI) with foreign aid (BLN-OECF INP22) for initial activities such as surveys, retaining and dredging.

The Tumumpa Fishing Port (PPP) Tumumpa is one of the supporting facilities provided by the technical implementation unit (UPTD) from development and coaching hall of fish catching (BP3I), based on the Regional Regulation Decree (PERDA) of North Sulawesi Province Number 3 Year 2008 regarding the organization and The working prosedure of marine and fisheries office that led by a head of the hall who in the execution of his duties is responsible to the Head of Marine and Fisheries Service of North Sulawesi Province.

In the sale of ice blocks, ice block factory in Tumumpa Fishery Port (PPP) can only sell ice per beam because they do not have ice crusher, ice blocks that will be sold to fishermen with size $80 \mathrm{~kg}$ per block and sold for Rp 23.000, - I block.
\end{abstract}

Keywords: ice block, decision making, survey methods, demand

\section{Abstrak}

Sektor kelautan dan perikanan memiliki potensi besar sebagai sektor unggulan dan penggerak utama pembangunan perekonomian daerah menuju Sulawesi Utara yang maju, mandiri dan sejahtera. Hal ini disebabkan karena sektor ini memiliki keunggulan komparatif dibanding sektor lainnya berupa ketersediaan sumberdaya alam yang sangat besar dan mempunyai potensi ekonomi yang luar biasa, yang mampu menghasilkan produk dan jasa dengan daya saing tinggi, sepanjang dapat mengelolanya dengan tepat. Menurut Kementerian Kelautan dan Perikanan (KKP), ketersediaan sumberdaya alam yang ada di daratan semakin terbatas, khususnya yang berbasiskan lahan, sejalan dengan bertambahnya penduduk dan berkembangnya kegiatan ekonomi sebagai dampak dari pelaksanaan pembangunan. Tujuan penelitin untuk mengetahui bagaimana pengambilan keputusan dari persediaan es balok dan untuk mengidentifikasi hal apa saja yang mepengaruhi keputusan persediaan es balok di Pelabuhan Perikanan Pantai (PPP) Tumumpa Kota Manado. Metode yang digunakan dalam penelitian ini yaitu metode survei dan metode partisipatif. Data yang dikumpulkan berupa data primer dan data sekunder serta analisis data yang digunakan yaitu analisis deskriptif kualitatif dan analisis deskriptif kuantitatif.

Pelabuhan perikanan adalah pelabuhan khusus yang dipergunakan sebagai pangkalan kegiatan penangkapan ikan dan dilengkapi dengan berbagai fasilitas sejak ikan didaratkan sampai didistribusikan. Pelabuhan Perikanan Pantai 
(PPP) terletak di Kelurahan Tumumpa II Kecamatan Tuminting Kota Manado mempunyai letak geografis $1^{\circ} 31^{\prime 2} 21^{\prime \prime}$ LU dan 124'50'28" BT, dengan jarak lokasi dari pusat kota kurang lebih 7 km. Lokasi seluas 4 (empat) Ha di bangun sejak tahun 1993 yang di kenal dengan nama Pangkalan Pendaratan Ikan (PPI) dengan dana bantuan luar negeri (BLN-OECF INP-22) untuk kegiatan awal seperti survei, penahan tanah dan pengerukan.

Pelabuhan Perikanan Pantai (PPP) Tumumpa merupakan salah satu fasilitas penunjang yang di sediakan unit pelaksana teknis dinas (UPTD) balai pengembangan dan pembinaan penangkapan ikan (BP3l), berdasarkan surat keputusan peraturan daerah (PERDA) Provinsi Sulawesi Utara Nomor 3 Tahun 2008 tentang organisasi dan tata kerja Dinas Kelauan dan Perikanan dipimpin oleh seorang kepala balai yang dalam pelaksanaan tugasnya bertanggung jawab kepada Kepala Dinas Kelautan dan Perikanan Provinsi Sulawesi Utara.

Dalam kegiatan penjualan es balok, pabrik es balok yang ada di Pelabuhan Perikanan Pantai (PPP) Tumumpa hanya dapat menjual es per balok di karenakan belum mempunyai mesin penghancur es, es balok yang akan di jual kepada nelayan dengan berukuran $80 \mathrm{~kg}$ per balok dan dijual seharga Rp 23.000,-/balok.

Kata Kunci : es balok, pengambilan keputusan, metode survey

\section{PENDAHULUAN}

Utara mengacu pada tujuan pembangunan perikanan dan kelautan nasional serta potensi sumber daya alam, sehingga sektor perikanan dan kelautan menjadi salah satu program unggulan pembangunan ekonomi Sulawesi Utara. Menurut Badan Pusat Statistik Provinsi Sulawesi Utara, produksi perikanan tangkap pada 2015 sebesar 285.265.60 ton, dan untuk perikanan budidaya laut sebesar 339.578.19 ton, budidaya Tambak 702.86 ton, budidaya Kolam 68.597.52 ton, budaya Keramba 299.92 ton, budidaya Jaring Apung 54.661.19 ton, budidaya sawah 13.055 .65 ton, budidaya Jaring Tancap 1.806.56 ton. Berdasarkan potensi perikanan yang cukup besar serta perkembangannya baik di bidang usaha penangkapan, maupun budidaya, maka pemerintah menetapkan subsektor perikanan sebagai salah satu sektor penggerak pembangunan (Badan Pusat Statistik, 2015).

Penanganan hasil tangkapan di Pelabuhan Perikanan Pantai Tumumpa ada tiga tahap yaitu penanganan hasil tangkapan di atas kapal, penanganan dipelabuhan perikanan dan penanganan selama pendistribusian. Menurut Irwan
(1995) ikan yang mengalami pergerakan sebelum mati akan mengalami kondisi rigor mortis (keadaan kaku) lebih cepat dibandingkan dengan ikan yang tidak banyak bergerak sebelum mati. Semakin banyak ikan bergerak semakin cepat pula mengalami kekakuan dan juga makin rendah daya simpannya. Peletakan ikan kedalam palka dilakukan pula dengan pemberian es. Es digunakan oleh para nelayan di PPP Tumumpa sebagai bahan pengawet, nelayan juga harus memperhatikan es yang akan digunakan terutama untuk kapal yang beroperasi dalam waktu yang cukup lama.

Ikan merupakan komoditi yang mudah rusak dan cepat membusuk, sehingga ikan memerlukan penanganan yang cepat dan cermat dalam upaya mempertahankan mutu hasil perikanan. Dalam penanganan ikan segar diupayakan suhu selalu rendah mendekati $0^{\circ} \mathrm{C}$ dan dijaga jangan sampai suhu naik akibat terkena sinar matahari atau kekurangan es. Penanganan ikan harus dilakukan secepat mungkin untuk menghindari kemunduran mutu ikan sehingga diperlukan bahan dan media pendinginan yang sangat cepat dalam menurunkan suhu ikan pada pusat 
thermal ikan. Suhu merupakan salah satu faktor yang mempengaruhi tingkat kesegaran ikan. Tingkat kesegaran ikan akan semakin cepat menurun atau ikan akan mudah menjadi busuk pada suhu tinggi dan sebaliknya pembusukan akan dapat dihambat pada suhu rendah (Suparno et al, 1993).

Kelurahan Tumumpa II Kecamatan Tuminting terletak di bagian utara Kota Manado merupakan salah satu dari beberapa kelurahan yang ada di Kota Manado. Pelabuhan Perikanan Pantai (PPP) yang ada di Tumumpa adalah tempat yang disediakan untuk pelaksana sistem bisnis perikanan dan didukung dengan kegiatan pemerintah, pelabuhan perikanan berbagai fasilitas yang sangat penting dalam menunjang kegiatan operasional penangkapan ikan, berbagai fasilitas yang telah disediakan seperti SPBU, air bersih, dan pabrik es balok.

\section{Tujuan dan Manfaat Penelitian}

Penelitian ini bertujuan untuk mengetahui bagaimana pengambilan keputusan dari persediaan es balok dan untuk mengidentifikasi hal apa saja yang mepengaruhi keputusan persediaan es balok di Pelabuhan Perikanan Pantai (PPP) Tumumpa Kota Manado.

Manfaat penelitian ini adalah : 1) Sebagai sarana untuk menerapkan ilmu pengetahuan yang telah diperoleh selama kuliah melalui praktek yang dilakukan langsung di lapangan. 2) Sebagai salah satu syarat untuk memperoleh gelar sarjana pada Fakultas Perikanan dan IImu Kelautan Universitas Sam Ratulangi.

\section{METODE PENELITIAN}

Metode yang digunakan dalam penelitian ini adalah metode survei.
Menurut Hamdi dan Baharudin (2012), survei adalah suatu penelitian yang dilakukan dengan cara mengumpulkan data dan menafsirkan data secara umum sebagai apa yang tersedia di lapangan. Survei dapat dilakukan dengan cara sensus maupun sampling. Dalam pengambilan data untuk penelitian penulis menggunakan cara sensus yaitu cara pengambilan data secara menyeluruh atau bertanya langsung ke pada tenaga kerja pedagang es balok yang ada di Pelabuhan Perikanan Pantai Tumumpa Kota Manado.

Data yang dikumpulkan pada penelitian ini terdiri dari data primer dan data sekunder. Data primer diperoleh dari pengelolah pabrik es balok dan tenaga kerja melalui pengisian daftar pertanyaan (Kuisioner), sedangkan data sekunder diperoleh dari bahan bacaan yang berkaitan dengan data yang dibutuhkan serta mengutip data yang berasal dari instansi terkait.

Data yang diperoleh dari hasil penelitian dianalisis dengan menggunakan analisis deskriptif kualitatif. Analisis deskriptif kualitatif yaitu analisis dengan memberikan gambaran serta keterangan dengan menggunakan kalimat penulis secara sistematis dan mudah dimengerti sesuai dengan data yang diperoleh. Sedangkan untuk analisis deskriptif kuantitatif merupakan analisis data dengan memberikan bahasan atau kajian terhadap data yang ada dengan menggunakan perhitungan yaitu dengan munggunakan rumus analisis Uji beda pada masing-masing variabel, digunakan statistik uji t.

Rumus :

$$
t=\frac{\left(\bar{X}_{1}-\bar{X}_{2}\right)-\left(\mu_{1}-\mu_{2}\right)}{S p \sqrt{\left(\frac{1}{n_{1}}+\frac{1}{n_{2}}\right)}}
$$




$$
\begin{aligned}
& S p^{2}=\frac{\left(n_{1}-1\right) S_{1}^{2}-\left(n_{2}-1\right) S_{2}^{2}}{n_{1}+n_{2}-2} \\
& \mathrm{db}=\mathrm{n}_{1}+\mathrm{n}_{2}-2 \text { pada taraf } \alpha=5 \% .
\end{aligned}
$$

\section{HASIL DAN PEMBAHASAN}

\section{Keadaan Umum Pelabuhan Perikanan Pantai (PPP) Tumumpa}

Pelabuhan Perikanan Pantai (PPP) terletak di Kelurahan Tumumpa II Kecamatan Tuminting Kota Manado Provinsi Sulawesi Utara mempunyai letak geografis $1^{\circ} 31^{\prime} 21^{\prime \prime}$ LU dan $124^{\circ} 50^{\prime 2} 28^{\prime \prime} \mathrm{BT}$, dengan jarak lokasi dari pusat kota kurang lebih $7 \mathrm{~km}$. Lokasi seluas 4 (empat) Ha di bangun sejak tahun 1993 yang di kenal dengan nama Pangkalan Pendaratan Ikan (PPI) dengan dana bantuan luar negeri (BLNOECF INP-22) untuk kegiatan awal seperti survei, penahan tanah dan pengerukan. Kondisi hingga saat ini sangat memerlukan perbaikan dan rehabilitasi, disamping adanya tahapan pembangunan sarana/prasarana dasar sebagaimana syarat Pelabuhan Perikanan Pantai (PPP) yang ditetapkan sejak tahun 2005 seperti peningkatan status dermaga pelabuhan, asrama pelatihan nelayan, pos keamanan satu atap dan fasilitas pendukung lainnya.

Pelabuhan Perikanan Pantai (PPP) Tumumpa merupakan salah satu fasilitas penunjang yang di sediakan unit pelaksana teknis dinas (UPTD) balai pengembangan dan pembinaan penangkapan ikan (BP3I), berdasarkan surat keputusan peraturan daerah (PERDA) Provinsi Sulawesi Utara Nomor 3 Tahun 2008 Tentang organisasi dan tata kerja Dinas Kelauan dan Perikanan dipimpin oleh seorang kepala Balai yang dalam pelaksanaan tugasnya bertanggung jawab kepada Kepala Dinas Kelautan dan Perikanan Provinsi
Sulawesi Utara. Dalam pelaksanaan fungsinya, UPTD Balai Pengembang dan Pembinaan Penangkapan Ikan (BP3I) membawahi pelaksanaan kegiatan operasional Pelabuhan Perikanan Pantai Tumumpa Kota Manado, Pelabuhan Perikanan Pantai Dagho Kabupaten Kepulauan Sangihe, dan Pangkalan Pendaratan Ikan Dodepo Kabupaten Bolaang Mangondow Selatan dengan kedudukan secara administratif di Pelabuhan Perikanan Pantai Tumumpa Kota Manado.

\section{Fasilitas-Fasilitas (PPP) Tumumpa}

\section{Fasilitas Pokok}

Fasilitas-fasilitas pokok yang berfungsi sebagai pelindung bagi kapalkapal sewaktu keluar masuk pelabuhan dan sewaktu berada di pelabuhan dengan berbagai aktivitas, yang tergolong dalam fasilitas fungsional yaitu

(1) Tanah/lahan seluas $4 \mathrm{Ha}$.

(2) Breakwater : berungsi sebagai pemecah gelombang dengan ukuran $465 \mathrm{M}$.

(3) Kolam pelabuhan : untuk menampung kapal dalam melakukan berth time (waktu sandar) selama dalam pelabuhan seluas $3,1 \mathrm{Ha}$.

(4) Dermaga : dermaga yang terdapat di pelabuhan terdiri atas dermaga utama dan dermaga perikanan. Dermaga utama seluas $1000 \mathrm{~m}^{2}$ dan dermaga perikanan dengan luas $1 \mathrm{Ha}$.

(5) Jalan Kompleks yang ada di kompleks pelabuhan disediakan untuk kelancaran arus kendaraan yang keluar masuk di PPPT yang berukuran $1500 \mathrm{~m}^{2}$ dengan kontruksi jalan aspal.

(6) Drainase berfungsi untuk menjaga kebersihan kompleks PPPT yang 
berukuran $1200 \mathrm{~m}^{2}$ dengan kontruksi beton.

(7) Alur pelayaran berungsi untuk memberi jalan kepada kapal untuk memasuki wilayah pelabuhan dengan aman dan mudah dalam masukdi PPPT yang berukuran 50 Ha.

\section{Fasilitas Fungsional}

Fasilitas-asilitas fungsional yang berfungsi untuk keperluan kelancaran berbagai aktivitas kerja dan pelayanan di daerah pelabuhan untuk meningkatkan mutu dan memanfaatkan pelabuhan, yang tergolong dalam fasilitas fungsional yaitu :

(1) Gedung TPI dengan luas $525 \mathrm{~m}^{2}$

(2) Air bersih 10 Ton

(3) Kantor administrasi $130 \mathrm{~m}^{2}$

(4) Listrik 5.500 Waat

(5) Ipal TPI $18 \mathrm{~m}^{2}$

(6) Instalansi BBM/SPDN $407 \mathrm{~L}$

(7) Pagar keliling $250 \mathrm{~m}$

\section{Fasilitas Penunjang}

Fasilitas penunjang merupakan fasilitas yang secara tidak langsung mendukung dan mempertinggi peranan pelabuhan perikanan, fasilitas penunjang yang terdapat di PPP Tumumpa yaitu :

(1) Balai pertemuan nelayan $180 \mathrm{~m}^{2}$

(2) Mess operator 3 unit

(3) Toilet $30 \mathrm{~m}^{2}$

(4) Pos jaga $16 \mathrm{~m}^{2}$

(5) Gudang es $48 \mathrm{~m}^{2}$

(6) Bengkel $72 \mathrm{~m}^{2}$

(7) Bangsal kerja 1 unit

(8) Pintu gerbang pos 1 unit

(9) Rumah dinas $80 \mathrm{~m}^{2}$

(10) Freezer 1 unit

\section{Jumlah Armada Kapal Penagkap Ikan di (PPP) Tumumpa}

Selang tahun 2016 jumlah kapal pengankap ikan yang berpangkalan di Pelabuhan Perikanan Pantai (PPP) Tumumpa sebanyak 166 unit. Kapal penangkap ikan ini terdiri dari jenis alat penangkapan ikan ada 4 (empat) jenis yakni Purse Sein sebanyak 72 unit, Pole and Line sebanyak 50 unit, Light Boat sebanyak 36 unit, Hand Line 8 unit.

Tabel. Jumlah Armada Kapal Penangkap Ikan (PPP) Tumumpa

\begin{tabular}{|c|c|c|c|c|}
\hline NO. & UKURAN KAPAL & TAHUN 2015 & TAHUN 2016 & KETERANGAN \\
\hline 1. & $<10 \mathrm{GT}$ & 8 & 8 & Hand Line \\
\hline 2. & $10 \mathrm{GT}-20 \mathrm{GT}$ & 24 & 36 & Light Boat \\
\hline 3. & $20 \mathrm{GT}-30 \mathrm{GT}$ & 88 & 50 & Pole and Line \\
\hline 4. & $>30 \mathrm{GT}$ & 31 & 72 & Purse Sein \\
\hline & JUMLAH & 151 & 166 & \\
\hline
\end{tabular}

Sumber : UPTD Balai Pengembangan dan Pembinaan Penangkapan Ikan (BP3I) Provinsi Sulawesi Utara, 2017.

Untuk pertambahan kapal dengan dibawah 10 GT karena ada beberapa kapal penangkap ikan khususnya jenis alat tangkap penangkap ikan pole and line yang sebelumnya berpangkalan di pelabuhan Manado/Kalimas, berpindah pangkalan di Pelabuhan Perikanan Pantai (PPP) Tumumpa. Hal yang sama juga terjadi untuk pertambahan kapal penangkap ikan dengan bobot kapal 10 - 20 GT. Salah satu penyebab perpindahan pangkalan ini adalah untuk mendapatkan BBM Solar yang yang ada di SPDN Tumumpa. Hal menarik justru terjadi pada data jumlah kapal penangkap ikan dengan bobot kapal 20 
- 30 GT dan diatas 30 GT. Hal ini terjadi disebabkan karena adanya kegiatan verifikasi/pengukuran ulang kapal perikanan yang dilakukan oleh pihak Kantor Syahbandar Dan Otoritas Pelabuhan (KSOP) Manado selama tahun 2015 hingga dengan tahun 2016. Hal tersebut mengakibatkan adanya penambahan kapal penangkap ikan dengan bobot kapal lebih besar dari 30 GT dan berkurangnya kapal penangkap ikan dengan bobot kapal penangkap 20 - 30 GT, karena pada saat verifikasi/pengukuran ulang kapal perikanan, banyak ditemukan kapalkapal perikanan yang pada awalnya berbobot lebih kecil dari 30 GT ternyata menjadi lebih besar dari 30 GT. Dengan demikian semua domumen kapal perikanan yang bersangkutan muali grosse akte (kepemilikan), pass besar (surat laut), Surat ljin Penangkapan Ikan (SIPI), Surat ljin Usaha Perikanan (SIUP) mengalami perubahan, dan menindak lanjuti konsekuensi perubahan bobot kapal tersebut maka Kementerian Kelautan Dan Perikanan Direktorat Jenderal Perikanan Tangkap melakukan kegiatan Gerai Perijinian Kapal Perikanan yang dilaksanan di Pelabuhan Perikanan Pantai (PPP) Tumumpa sebanyak 2 (dua) kali yakni pada bulan Juli 2016 dan November 2016. Berdasarkan data pemilik kapal yang mengikuti kegiatan tersebut sebanyak 34 kapal perikana pada bulan Juli 2016 dan sebanyak 26 kapal perikanan bulan November 2016. Jumlah kapal perikanan yang mengikuti kegiatan Gerai perijinan kapal perikanan tersebut sudah termasuk kapal perikanan yang berpangkalan di luar Pelabuhan Perikanan Pantai (PPP) Tumumpa.
Terhadap kondisi ini, diperlukan masih cukup banyak kapal perikanan yang belum menyesuaikan dokumen perijinan yang mereka miliki karena masih ada pemilik kapal yang sudah melakukan verifikasi/pengukuran ulang kapal perikanan, tetapi belum melanjutkan pengurusan dokumen kapal perikanan yang mereka miliki sesuai ketentuan perijinan yang terbuka, bahkan masih cukup banyak kapal perikanan yang belum melakukan verifikasi/pengukuran ulang kapal perikanan yang mereka miliki

\section{Analisis Keputusan Persediaan Es Balok \\ Penyediaan/Produksi Es Oleh Pabrik Es Balok Di PPP Tumumpa}

Perusahaan pabrik es balok di Pelabuhan Perikanan Pantai (PPP) Tumumpa merupakan salah satu pabrik es yang dikelola oleh pelabuhan. Produk pabrik es ini pemasaranya ditujukan untuk operasi keperluan penangkapan ikan. Peran penting penyediaan es balok dalam kaitannya dengan aktifitas penangkapan ikan adalah sangat besar di mana kapal-kapal penangkapan dapat menjaga kualittas hasil tangkapannya.

Pengamatan selama melakukan penelitian di Pelabuhan Perikanan Pantai (PPP) Tumumpa bahwa kegiatan produksi pabrik es telah dikoordinasikan dengan cukup baik dalam tahapantahapan produksinya maupun pelayanannya. Es balok yang ada di Pelabuhan Perikanan Pantai Tumumpa diproduksi dengan bahan baku utama yaitu air sumur dan garam. Kapasitas produksi es dari pabrik dapat terjual habis sebanyak 16-24 ton per hari. 
Tabel. Tingkat Produksi dan Penjualan Es Balok di PPP Tumumpa.

\begin{tabular}{|c|c|c|c|}
\hline No. & Bulan & Produksi Es (Kg) & Penjualan Es (Kg) \\
\hline 1. & Januari & 96.000 & 80.000 \\
\hline 2. & Februari & 144.000 & 140.000 \\
\hline 3. & Maret & 144.000 & 136.000 \\
\hline 4. & April & 144.000 & 141.600 \\
\hline 5. & Mei & 144.000 & 140.000 \\
\hline 6. & Juni & 144.000 & 139.200 \\
\hline 7. & Juli & 96.000 & 92.000 \\
\hline 8. & Agustus & 96.000 & 88.000 \\
\hline 9. & September & 96.000 & 93.600 \\
\hline 10. & Oktober & 96.000 & 92.000 \\
\hline 11. & November & 96.000 & 92.800 \\
\hline 12. & Desember & 80.000 & 80.000 \\
\hline \multicolumn{2}{|c|}{ Total Es (Kg) } & 1.376 .000 & 1.315 .200 \\
\hline
\end{tabular}

\section{Data Kebutuhan Air dan Garam}

Dalam satu kali produksi es balok, air dan garam yang akan digunakan dengan komposisi garam sebanyak $30 \mathrm{~kg}$ dan 6000 liter air. Data jumlah kebutuhan air dan garam periode Januari hingga Desember 2016 terdapat pada Tabel 7.

Tabel. Data Kebutuhan Air dan Garam.

\begin{tabular}{|c|c|c|c|}
\hline No. & Periode & $\begin{array}{c}\text { Jumlah } \\
\text { Air (liter) }\end{array}$ & $\begin{array}{c}\text { Jumlah } \\
\text { Garam (kg) }\end{array}$ \\
\hline 1. & Januari & 30.000 & 75 \\
\hline 2. & Februari & 36.000 & 180 \\
\hline 3. & Maret & 36.000 & 180 \\
\hline 4. & April & 36.000 & 180 \\
\hline 5. & Mei & 36.000 & 180 \\
\hline 6. & Juni & 36.000 & 180 \\
\hline 7. & Juli & 30.000 & 75 \\
\hline 8. & Agustus & 30.000 & 75 \\
\hline 9. & September & 30.000 & 75 \\
\hline 10. & Oktober & 30.000 & 75 \\
\hline 11. & November & 30.000 & 75 \\
\hline 12. & Desember & 30.000 & 75 \\
\hline $\begin{array}{r}\text { Total Kebutuhan Air } \\
\text { dan Garam }\end{array}$ & 390.000 & 1425 \\
\hline
\end{tabular}

Data Primer 2016.
Berdasarkan pada tabel 7 dapat diketahui jumlah kebutuhan air dan garam di Palabuhan Perikanan Pantai (PPP) Tumumpa yaitu pada bulan Februari sampai pada bulan Juni kebutuhan air dan garam akan meningkat, sedangkan pada bulan Juli sampai dengan bulan Januari kebutuhan air dan garam akan menurun.

\section{Potensi Permintaan Nelayan Terhadap Es Balok}

Perusahaan pabrik es balok yang ada di Pelabuhan Perikanan Pantai Tumumpa merupakan perusahaan yang memfokuskan usaha dalam bidang produksi dan penjual sebagai supplier produk es balok bagi nelayan. Dalam menjalankan kegiatan usahanya, pihak perusahaan menuntut agar kinerja penjualan dapat ditingkatkan demi pencapaian pendapatan yang maksimal. Untuk lebih jelas potensi permintaan nelayan terhadap es balok dapat dilihat pada tabel dibawah ini. 
Tabel. Analisis Potensi Permintaan Nelayan Terhadap Es Balok

\begin{tabular}{|c|c|c|c|c|}
\hline No. & Bulan & Produksi Es (Kg) & Permintaan Nelayan (Kg) & Nilai Penjualan (Rp) \\
\hline 1. & Januari & 96.000 & 16.000 & 4.600 .000 \\
\hline 2. & Februari & 144.000 & 32.000 & 9.200 .000 \\
\hline 3. & Maret & 144.000 & 24.000 & 6.900 .000 \\
\hline 4. & April & 144.000 & 32.000 & 9.200 .000 \\
\hline 5. & Mei & 144.000 & 32.000 & 9.200 .000 \\
\hline 6. & Juni & 144.000 & 24.000 & 6.900 .000 \\
\hline 7. & Juli & 96.000 & 16.000 & 4.600 .000 \\
\hline 8. & Agustus & 96.000 & 12.000 & 3.450 .000 \\
\hline 9. & September & 96.000 & 16.000 & 4.600 .000 \\
\hline 10. & Oktober & 96.000 & 8.000 & 2.300 .000 \\
\hline 11. & November & 96.000 & 16.000 & 4.600 .000 \\
\hline 12. & Desember & 80.000 & 16.000 & 4.600 .000 \\
\hline \multicolumn{5}{|c|}{ Potensi Permintaan } \\
Nelayan & 1.376 .000 & $\mathbf{2 4 4 . 0 0 0}$ & 69.000 .000 \\
\hline
\end{tabular}

Sumber : Data Primer, 2016.

Pada tabel 8 menunjukan bahwa jumlah permintaan nelayan terhadap es balok. Pada bulan Februari, April dan Mei permintaan nelayan akan es balok meningkat sebesar 32.000,- $\mathrm{Kg}$ dengan nilai penjualan sebesar Rp 9.200.000,dan paling sedikit pada bulan Oktober permintaan akan es balok sebesar
$8.000,-\mathrm{Kg}$ dengan nilai penjualan $\mathrm{Rp}$ 2.300.000,- di karenakan pabrik es tidak mampu memenuhi kebutuhan kapal penangkapan.

Hasil analisis menggunakan statistik uji t untuk perbandingan produksi dan potensi permintaan nelayan, didapat hasil sebagai berikut :

t-Test: Two-Sample Assuming Unequal Variances

\begin{tabular}{lrr}
\hline & Produksi Es (Kg) & Permintaan Nelayan $(\mathrm{Kg})$ \\
\hline Mean & $114.666,67$ & $20.333,33$ \\
Variance & $690.424 .242,42$ & $68.242 .424,24$ \\
Observations & 12 & 12 \\
Hypothesized Mean Difference & 0 & 13 \\
Df & 11,86397717 & \\
t Stat & $1,19784 \mathrm{E}-08$ \\
P(T<=t) one-tail & 1,770933396 \\
t Critical one-tail & $2,39568 \mathrm{E}-08^{* *}$ & \\
P(T<=t) two-tail & 2,160368656 & \\
t Critical two-tail & &
\end{tabular}

Keterangan : $\left({ }^{* *}\right)$ berbeda sangat nyata

Hasil analisis statistik uji $t(p<0,05)$ menunjukkan perbedaan sangat nyata antara produksi es balok dan permintaan nelayan. Hal ini menunjukkan adanya selisih yang signifikan antara jumlah es balok yang diproduksi dan jumlah es balok yang dibutuhkan nelayan di PPP Tumumpa.

Faktor-Faktor Yang Mempengaruhi Persediaan Es Balok di Pelabuhan Perikanan Pantai (PPP) Tumumpa 
Besar kecilnya persediaan bahan baku yang dimiliki oleh perusahaan ditentukan berbagai faktor antara lain kapasitas yang dibutuhkan untuk melindungi jalannya perusahaan terhadap gangguan kehabisan persediaan yang akan dapat menghambat atau mengganggu berjalannya proses produksi. Pada tahun 2016 jumlah kapal penankapan ikan yang bersandar di pelabuhan perikanan pantai Tumumpa sebanyak 166 kapal tergantung ukuran kapal yang berbedabeda dan lama lama penangkapan.

Tabel. Tingkat Kebutuhan Perbekalan Es Untuk Keperluan Penangkapan Ikan di Pelabuhan Perikanan Pantai Tumumpa.

\begin{tabular}{|c|c|c|c|c|}
\hline Ukuran (GT) & $\begin{array}{c}\text { Jumlah } \\
\text { Trip }\end{array}$ & Kebutuhan Es/Trip (Ton) & Jumlah Kapal & $\begin{array}{c}\text { Total Kebutuhan } \\
\text { Es/Tahun (Ton) }\end{array}$ \\
\hline$<10$ GT & 1 & 5 & 8 & 40 \\
\hline 10 GT - 20 GT & 1 & 8 & 36 & 288 \\
\hline 20 GT - 30 GT & 1 & 12 & 50 & 600 \\
\hline$>30$ GT & 1 & 77 & 72 & 1,540 \\
\hline \multicolumn{2}{|c|}{ Total } \\
\hline
\end{tabular}

Sumber : Data Primer 2016.

t-Test: Two-Sample Assuming Unequal Variances

\begin{tabular}{|c|c|c|}
\hline & Kebutuhan Es/Trip (Ton) & Total Kebutuhan Es/Tahun (Ton) \\
\hline Mean & 17 & 411.3333333 \\
\hline Variance & 148.8 & 70634.66667 \\
\hline Observations & 6 & 6 \\
\hline Hypothesized Mean Difference & 0 & \\
\hline Df & 5 & \\
\hline t Stat & $-3,630556508$ & \\
\hline$P(T<=t)$ one-tail & 0,007525884 & \\
\hline t Critical one-tail & 2,015048372 & \\
\hline$P(T<=t)$ two-tail & 0,015051769 & \\
\hline $\mathrm{t}$ Critical two-tail & 2,570581835 & \\
\hline
\end{tabular}

Hasil statistik uji $t(p>0,05)$ menunjukkan baha antara kebutuhan es/trip dan total kebutuhan es/tahun jumlah yang terjual tidak berbeda nyata. Hal ini menggambarkan bahwa baik jumlah kebutuhan es/trip hampir semua dapat di serap kapal penangkapan ikan.

\section{KESIMPULAN DAN SARAN Kesimpulan}

Berdasarkan hasil penelitian dan pembahasan sebelumnya dapat diambil kesimpulan sebagai berikut:
1. Berdasarkan hasil analisis terhadap potensi permintaan nelayan terhadap es balok, didapat hasil sebesar 17,75\%. Hal ini menggambarkan bahwa masih tersisa $82,27 \%$ kapasitas produksi yang masih tersisa. Hasil tidak signifikan antara produksi dan penjualan menandakan bahwa penjualan es balok di PPP Tumumpa bukan hanya nelayan, namun dibeli juga oleh pedagang perantara dan nelayan luar dari PPP Tumumpa. 
2. Hasil statistik uji $t \quad(p>0,05)$ menunjukkan bahwa antara produksi es balok dan jumlah yang terjual tidak berbeda nyata. Hal ini menggambarkan bahwa baik jumlah es balok yang diproduksi hampir semua dapat diserap oleh pasar, dalam hal ini dibeli oleh nelayan, pedagang perantara dan rumah tangga nelayan.

3. Penjualan es balok dengan berukuran $80 \mathrm{Kg} /$ balok dan dijual seharga Rp 23.000,-/balok, setiap kali produksi sebanyak $24.000 \mathrm{Kg}$ - $32.000 \mathrm{Kg}$ dan membutuhkan waktu yang lama untuk satu kali produksi yaitu minimal 12 jam dan maksimal 16 jam setiap kali produksi.

\section{Saran}

1. Sebaiknya pihak Perusahaan es balok yang ada di pelabuhan perikanan pantai (PPP) Tumumpa Kota Manado lebih memperhatikan kebersihan yang ada di sekitar khususnya untuk penyimpanan es balok.

2. Sebaiknya pihak pelabuhan perikanan pantai (PPP) Tumumpa Perlu menyediakan mesin Generator Set (genset) di pabrik es, supaya terhindar dari mati listrik secara tiba-tiba.

\section{DAFTAR PUSTAKA}

Badan Pusat Satistik, 2016. Provinsi Sulawesi Utara DalamAngka.

Benny Alexanri. 2009. Manajemen Keuangan Bisnis Teori dan Soal. Alfabeta: Bandung.
Christanti, N. 2005. Tingkat Penyediaan Dan Kebutuhan Es Untuk Kapal Ikan Di Pelabuhan Perikanan Nusantara Pekalongan. Skripsi. Bogor (ID): Fakultas Perikanan Dan IImu Kelautan. Institute Pertanian Bogor.

Dagum, M. Save. 2016. Kamus Besar IImu Pengetahuan. Jakarta : Lembaga Pengkajian Kebudayaan Nusantara (LPKN).

Dewanti Taine. 2015. Analisis Keputusan Persediaan Ikan Asap di Kelurahan Girian Atas dan Girian Bawah Kecamatan Girian Kota Bitung Provinsi Sulawesi Utara. Skripsi. Fakulttas Perikanan dan IImu Kelautan. UNSRAT.

Gorys, Keraf. 1982. Eksposisi dan Deskripsi. Endelores: Nusa Indah.

Hamdi, A.S dan Baharuddin, E. 2012. Metode Penelitian Kuantitatif Aplikasi Dalam Penelitian. Deepublisher Publisher. JIn Kaliurang Yogyakarta.

Irawan A. 1995. Pengawetan Ikan Dan Hasil Perikanan. Solo.

Kamus Besar Bahasa Indonesia (KBBI). 2005. Definisi Deskripsi.

Kementrian Kelautan dan Perikanan. 2012. Kelautan dan Perikanan Dalam Angka 2011. KKP Jakarta. Jakarta.

Nur Bahagia, Senator. 2006. Sistem Ineventori. Penerbit ITB. Bandung.

Patton, MQ. 1990. Qualitative Evaluation Methods. SAGE. Beverly Hills.

Sedamaryanti dan Hidayat. 2002. Metodologi Penelitian. Mandar Maju. Bandung.

Suparno, et al 1993. Ikan-ikan Yang Kurang Di Manfaatkan Sebagai Pangan Bergizi Tinggi. Di Dalam Laporan Widyakarya Nasional Pangan Gizi. Jakarta.

Taylor, SJ dan R. Bogdan. 1984. Introduction To Qualitative Research Methods: The Search for Meanings, Second Edition. Jhon Wiley and Sons. Toronto.

Walpole, Ronald E., 1995, Pengantar Statistik Edisi 3 Alih Bahasa: Bambang Sumantri, Jakarta, Gramedia Pustaka Utama. 